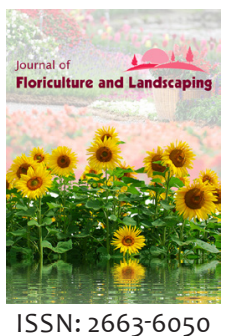

Received: December 31, 2019 Accepted: March 16, 2020 Published: March 23, 2020

*Corresponding Author: D.J. Bagyaraj Email: djbagyaraj@gmail.com

\section{Microbial consortium promotes growth of Zinnia and Balsam seedlings raised in pro trays}

\author{
D. Sukeerthi" ${ }^{1,2}$, N. Nikhil Sai', R. Ashwin', D.J. Bagyaraj"* \\ ${ }^{1}$ Centre for Natural Biological Resources and Community Development (CNBRCD), 41 RBI Colony, Anand Nagar, \\ Bengaluru - 560 024, Karnataka, India, 'St Joseph's College (Autonomous), 36, Lalbagh Road, Bengaluru - 560027 , \\ Karnataka, India
}

\section{ABSTRACT}

Zinnia and Balsam are flowering plants with high economic importance in floriculture. Inoculation of the planting medium with a beneficial microbial consortium is an innovative approach to produce quality and healthy seedlings in floriculture. In the present study the influence of a microbial consortium of the arbuscular mycorrhizal fungus (AMF) Funneliformis mosseae and a plant growth promoting rhizobacterium (PGPR) Bacillus sonorensis on flowering plants Zinnia and Balsam in pro-trays under poly house conditions was investigated. Estimation of various plant growth parameters such as plant height, stem diameter, bio-volume index, vigour index, plant strength, fresh weight, dry weight and nutrient uptake was carried out to analyse the ability of the consortium to improve seedling growth. Microbial parameters such as mycorrhizal root colonization and spore count, and population of PGPR in substrate was also studied. The results suggested that inoculating the substrate in pro trays before sowing the seeds with the consortium increased plant growth significantly compared to the uninoculated plants.

KEYWORDS: Bacillus sonorensis, Balsam, Glomus mosseae, Pro trays, Zinnia

\section{INTRODUCTION}

Sustainable agriculture aims at maintaining soil fertility for a long time and achieving optimized yield using low input [1]. It focuses on producing long term crops and increases the biodiversity by providing a healthy environment for the organisms to live [2]. Biofertilizers are beneficial microorganisms which are introduced to soil to promote better plant growth [3]. Addition of beneficial microorganisms such as nitrogen fixers, phosphate solubilizers, PGPR, AMF etc. is beneficial to the plants and reduces the use of chemical fertilizers $[4,5]$. There are numerous methods for the application of these beneficial microbes for improving plant growth [6]. The Pro tray nursery is a recent technology widely gaining popularity for quality seedling production. Such seedlings have an independent area for each seedling; hence improved seed germination, better root development, easy handling, cheaper transportation and better establishment of the crop when transplanted in the main field $[7,8]$.

Zinnia belongs to the family Asteraceae. It is used as cut flowers, bedding plants and as companion plants as it attracts wasps and hummingbirds that deter cucumber pests and whiteflies respectively. Balsam belongs to the family Balsaminaceae. It produces beautiful flowers. Further it has useful medicinal properties, such as, its leaves and flowers are used to treat snake bites and skin burns respectively. It is also used to treat gastritis, constipation and also as a hair growth stimulant [9].

Soil harbours a large population of microorganisms. The highest concentration of microbial population is around the roots i.e. the rhizosphere region [10]. This particularly is due to the presence of sugars, amino acids, organic acids etc. in the root exudates $[11,12,13]$. PGPR are beneficial bacteria in the rhizosphere promoting plant growth by various mechanisms. [14] Direct mechanisms include nitrogen fixation, phosphate solubilisation, production of growth hormones, iron sequestration, etc. Indirect mechanisms include inhibition of plant pathogens through production of antibiotics and siderophores [6]. The PGPR Bacillus sonorensis is a Grampositive motile rod, forming endospores. It forms characteristic brown colonies on tyrosine agar [15].

AMF form symbiotic association with nearly $80 \%$ of the plants [16]. They facilitate uptake of diffusion limited nutrients and protect the plants against biotic and abiotic stresses in exchange for photosynthates of the plant $[17,18]$. Inoculation with AMF improving plant growth is well documented. Dual inoculation with AMF and PGPR significantly improving plant 
growth compared to single inoculation with either of them has been reported earlier in other plants [19]. Some workers have pointed out that the effect of the microbial consortium consisting of two or more microorganisms may or may not be greater than their individual effects [20]. The objective of the current work was to evaluate the effect of a microbial consortium consisting of AMF Funneliformis mosseae and the PGPR Bacillus sonorensis on the growth of flowering plants Zinnia and Balsam raised in pro trays under poly house conditions.

\section{MATERIALS AND METHODS}

The experiment was conducted at Centre for Natural Biological Resources and Community Development (CNBRCD), Bengaluru, India. The seeds of Zinnia and Balsam used in the study were procured from University of Agricultural Sciences, GKVK campus, Bengaluru, India.

\section{Inoculum Preparation}

Sub-culturing of B. sonorensis was done on Luria-Bertani (LB) agar plates and incubated at $37^{\circ} \mathrm{C}$ for 24 hours. A single colony from the sub-cultured plate was inoculated into $500 \mathrm{ml}$ of $\mathrm{LB}$ broth and incubated at $37^{\circ} \mathrm{C}$ for 24 hours. This was used for inoculation of the substrate in pro-trays. The bacterial population was enumerated by performing serial dilution of the culture and plating onto LB agar. F. mosseae culture was maintained in a polyhouse, using Chloris gayana (Rhodes grass) as the host and Vermiculite: Perlite: Soilrite in the ratio of 3:1:1 by volume $+8 \%$ sterilized soil as substrate. The plants were harvested 75 days after sowing (DAS) and finely chopped roots along with the substrate which contained spores and hyphae were air dried and used as inoculum. The number of infective propagules was determined using MPN method with 10-fold dilution $[21,22]$.

\section{Experimental Setup}

The cells of the pro trays were filled with $20 \mathrm{~g}$ of the substrate described above. There were two treatments for each plant type, 100 cells of two pro trays (each with 50 cells) served as uninoculated control and 100 cells of two pro trays served as inoculated treatment. A planting hole was made in the substrate and $\mathrm{lg}$ of F. mosseae inoculum (containing $2.2 \times 10^{3} \mathrm{IP} / \mathrm{g}$ ) and $2 \mathrm{ml}$ of $B$. sonorensis inoculum (containing $1.9 \times 10^{5} \mathrm{cfu} / \mathrm{ml}$ ) was added. The seeds were sown and watered regularly. Five $\mathrm{ml}$ of Ruakura nutrient solution without $\mathrm{P}$ was added to all the cells once in 10 days starting from 20 days after sowing [23].

\section{Parameters Evaluated}

Just before harvest, 60 DAS, plant growth parameters such as shoot length and stem diameter were determined. Shoot length was measured from the substrate surface to the tip of the plant. Stem diameter was measured $1 \mathrm{~cm}$ above the substrate. Root length and fresh weight of the plants were determined. The bio-volume index was calculated using the formula given by Hatchell [24]. The seed vigour was calculated using the standard formula [25]. The plant strength was calculated using a formula given by Maskina [26]. The samples were dried in a hot air oven at $60^{\circ} \mathrm{C}$ after which the dry weight was determined. The samples were then powdered and the nitrogen concentration was determined by Micro Kjelhdahl method [27]. Phosphorus concentration was estimated by vanadomolybdate phosphoric yellow colour method [28]. Potassium concentration was determined by Flame photometer method [29]. The

Table 1: Influence of microbial consortium on plant growth parameters of Zinnia and Balsam raised in pro trays 60 DAS

\begin{tabular}{|c|c|c|c|c|c|c|}
\hline \multirow[t]{2}{*}{ Growth parameters } & \multicolumn{3}{|c|}{ Zinnia } & \multicolumn{3}{|c|}{ Balsam } \\
\hline & Uninoculated control & Inoculated & T-test value & Uninoculated control & Inoculated & T-test value \\
\hline Shoot length $(\mathrm{cm})$ & 12.66 & 24.19 & $5.43 * *$ & 9.58 & 15.33 & $12.66 * *$ \\
\hline Root length (cm) & 10.02 & 13.39 & $4.61 * *$ & 6.84 & 13.91 & $16.39 * *$ \\
\hline Stem diameter $(\mathrm{mm})$ & 1.74 & 2.19 & $6.19 * *$ & 2.61 & 4.01 & $10.18 * *$ \\
\hline Bio-volume index & 39.68 & 82.25 & $11.80 * *$ & 43.71 & 117.66 & $13.19 * *$ \\
\hline Plant strength & 0.006 & 0.009 & $2.08 *$ & 0.005 & 0.007 & $6.39 * *$ \\
\hline Vigour index & 1100.71 & 2465.65 & $9.86 * *$ & 1444.5 & 2694.8 & $9.07 * *$ \\
\hline Number of flowers & 18 & 96 & $5.71 * *$ & - & - & - \\
\hline Fresh weight (g) & 0.49 & 1.77 & $4.57 * *$ & 0.94 & 2.77 & $12.22 * *$ \\
\hline Dry weight (g) & 0.12 & 0.33 & $12.07 * *$ & 0.08 & 0.20 & $10.84 * *$ \\
\hline
\end{tabular}
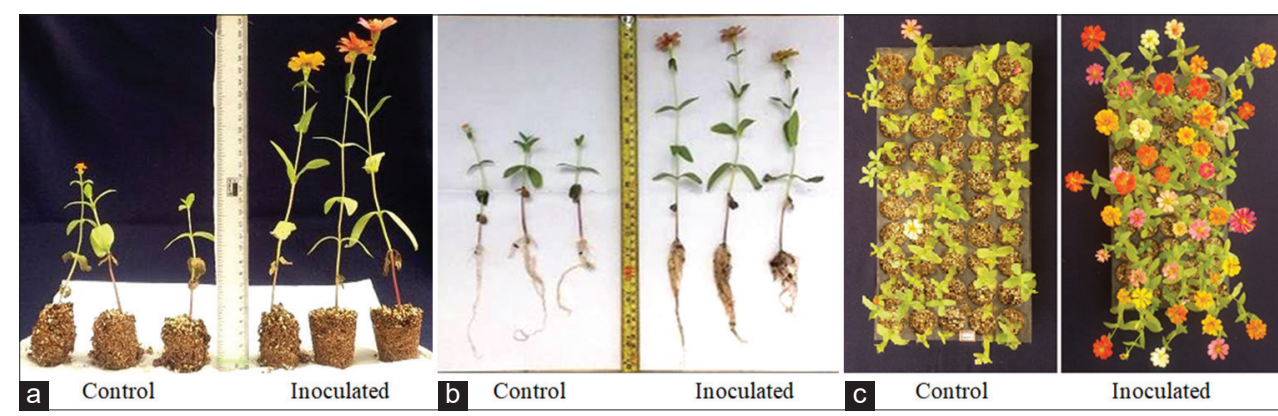

Figure 1: Effect of the microbial consortium on (a) shoot length, (b) root length and (c) flowering of Zinnia 60 DAS 
micronutrient analysis of the samples was performed using atomic absorption spectrophotometer with a hallow cathode lamp set to standard wavelengths [30]. The roots were washed and cut into $1 \mathrm{~cm}$ bits and subjected to trypan blue staining and the percent mycorrhizal root colonization was determined following the procedure of Philips and Hayman [31]. The AM spore number in the substrate was determined by wet-sieving and decantation method [32]. The B. sonorensis population in the substrate was enumerated by serial dilution and plating onto LB agar plates. [33] Data was subjected to T-test at a significance level $(\mathrm{P} \leq 0.05)$.

\section{RESULTS AND DISCUSSIONS}

There was an increase in shoot length, root length and stem diameter of zinnia and balsam when treated with the microbial consortium (Table 1). The plants treated with the microbial consortium showed a significant increase in the bio-volume index, plant strength and vigour index when compared to the uninoculated plants indicating that they grow more

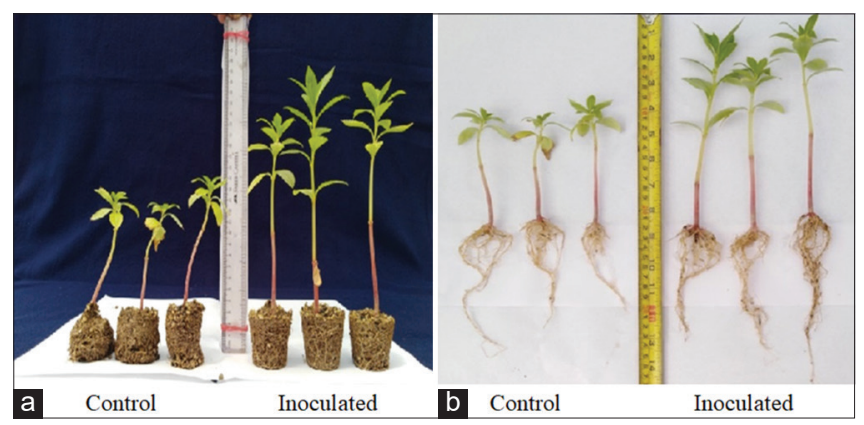

Figure 2: Effect of the microbial consortium on (a) shoot length and (b) root length of Balsam 60 DAS vigorously (Table 1). There was a significant increase in the fresh weight and dry weight of zinnia and balsam treated with the microbial consortium when compared to the control (Table 1 and Figures 1 and 2). Microbial consortium of $F$. mosseae $+B$. sonorensis added to the substrate in pro-trays enhancing seedling height, stem diameter, biovolume index, plant strength, vigour index and dry weight has been reported earlier in crops like tomato and capsicum [34]. There was also an increase in the number of flowers of zinnia in the inoculated plants compared to uninoculated plants in a span of 60 days (Table 1 and Figure 1). This indicated that the microbial consortium also induced flowering in zinnia. There are earlier reports that AMF and PGPR inoculation induced early flowering in some plants [35-36]. In balsam there was no flowering on 60 DAS. Inoculation of zinnia raised in pots with other AMF or PGPR have been reported to improve plant growth by earlier workers [37-39]. There was a significant difference between inoculated and uninoculated plants in the uptake of macro and micro nutrients in both zinnia and balsam (Table 2). The inoculated plants had 99\% mycorrhizal root colonization while the uninoculated zinnia and balsam had only 6 and $4 \%$ colonization respectively. The mycorrhizal spore numbers were absent in the uninoculated treatment while it was 21 and 35 per $50 \mathrm{~g}$ of substrate in zinnia and balsam respectively (Table 3 ). The population of $B$. sonorensis in the substrate was encountered only in the inoculated treatments (Table 3.). It can be concluded that the inoculation with microbial consortium consisting of AMF + PGPR resulted in improved growth of zinnia and balsam. This supports the work done by earlier workers in other plants under pot culture or field conditions [40-42]. There are very few reports on using microbial consortium in pro trays for enhancing seedling growth of vegetable crops [ 34 , 43-48]. Perhaps this is the first report on plants important in floriculture. Recently nurserymen, scientists and farmers have

Table 2: Effect of microbial consortium on the nutrient uptake of Zinnia and Balsam raised in pro trays 60 DAS

\begin{tabular}{|c|c|c|c|c|c|c|}
\hline \multirow[t]{2}{*}{ Nutrients } & \multicolumn{3}{|c|}{ Zinnia } & \multicolumn{3}{|c|}{ Balsam } \\
\hline & Uninoculated control & Inoculated & T-test value & Uninoculated control & Inoculated & T-test value \\
\hline Nitrogen (N) (\%) & 1.57 & 1.61 & $7.21^{* *}$ & 1.74 & 1.84 & $6.54 * *$ \\
\hline Phosphorus $\left(\mathrm{P}_{2} \mathrm{O}_{5}\right)(\%)$ & 0.15 & 0.23 & $9.83 * *$ & 0.04 & 0.14 & $7.32 * *$ \\
\hline Potassium $\left(\mathrm{K}_{2} \mathrm{O}\right)(\%)$ & 1.93 & 3.88 & $9.65^{* *}$ & 1.57 & 3.60 & $10.54 * *$ \\
\hline Calcium (Ca) $(\%)$ & 1.78 & 2.74 & $3.32 * *$ & 2.51 & 3.27 & $5.67 * *$ \\
\hline Magnesium (Mg) (\%) & 0.99 & 1.69 & $7.17 * *$ & 1.23 & 1.74 & $5.15^{* *}$ \\
\hline Zinc (Zn) (ppm) & 54.64 & 70.06 & $8.44^{* *}$ & 114.4 & 125.4 & $3.72 * *$ \\
\hline Copper (Cu) (ppm) & 44.88 & 60.44 & $13.67 * *$ & 66.62 & 79.07 & $6.56 * *$ \\
\hline Manganese $(\mathrm{Mn})(\mathrm{ppm})$ & 68.54 & 329 & $11.33 * *$ & 95.5 & 109.8 & $4.91 * *$ \\
\hline Boron (B) (ppm) & 68.03 & 113.5 & $13.86 * *$ & 69.63 & 73.68 & $13.81 * *$ \\
\hline Molybdenum (Mo) (ppm) & 70.69 & 74.71 & $6.12 * *$ & 85.76 & 94.66 & $12.80 * *$ \\
\hline Iron $(\mathrm{Fe})(\mathrm{ppm})$ & 2689 & 2994 & $6.84 * *$ & 3526 & 3984 & $12.74 * *$ \\
\hline
\end{tabular}

Table 3: Effect of microbial consortium on the mycorrhizal root colonization and spore count, and B. sonorensis population in the substrate of Zinnia and Balsam raised in pro trays 60 DAS

\begin{tabular}{|c|c|c|c|c|c|c|}
\hline & \multicolumn{3}{|c|}{ Zinnia } & \multicolumn{3}{|c|}{ Balsam } \\
\hline & Uninoculated control & Inoculated & T-test value & Uninoculated control & Inoculated & T-test value \\
\hline Percent mycorrhizal colonization & 6 & 99.99 & $4.74 * *$ & 4 & 99.99 & $3.52 * *$ \\
\hline Spore number/ $50 \mathrm{~g}$ of substrate) & 0 & 21 & $3.28 * *$ & 0 & 35 & $2.84 * *$ \\
\hline Bacillus sonorensis (CFU/g of substrate) & 0 & $1.95 \times 10^{4}$ & $3.12 * *$ & 0 & $1.5 \times 10^{4}$ & $3.83 * *$ \\
\hline
\end{tabular}


accepted the benefits of pro tray technology for raising crops like tomato, chilly, capsicum etc. The present study brings out that this technology can be extended to crops important in floriculture also.

\section{CONCLUSION}

The results obtained from this experiment brought out that the microbial consortium of F. mosseae $+B$. sonorensis is beneficial to the growth of flowering plants zinnia and balsam raised in pro trays. The results indicated that inoculation with microbial consortium helped to enhance germination, vigour index, plant strength, plant growth and nutrient uptake. The inoculated AMF and PGPR showed rhizosphere competence as evidenced by enhanced numbers in the substrate. Inoculation of the planting medium with beneficial microbial consortium is a biotechnological approach for producing healthy, vigorously growing seedlings. This technology can be used in floriculture nurseries for production of quality seedlings. It will also fetch higher income to the nurserymen.

\section{REFERENCES}

1. Bagyaraj DJ. Microbial Biotechnology for Sustainable Agriculture, Horticulture \& Forestry. New India Publishing Agency; 2011.

2. Altieri MA. Agroecology: The Science of Sustainable Agriculture. CRC Press; 2018.

3. Vessey JK. Plant growth promoting rhizobacteria as biofertilizers. Plant and Soil. 2003; 255:571-586.

4. Havlin JL, Tisdale SL, Nelson WL, Beaton JD. Soil fertility and fertilizers. $8^{\text {th }}$ Ed. Pearson Education India; 2016.

5. Bagyaraj DJ, Jamaluddin. Microbes for Restoration of Degraded Ecosystems. New India Publishing Agency; 2017.

6. Glick BR. Plant growth-promoting bacteria: mechanisms and applications. Scientifica. 2012;2012.

7. Bisen K, Keswani C, Mishra S, Saxena A, Rakshit A, Singh HB, Unrealized potential of seed biopriming for versatile agriculture. In: Nutrient Use Efficiency: from Basics to Advances, Rakshit A, SinghHB, Sen A(Ed.), Springer, New Delhi. 2015; 193-206.

8. Mahmood A, Turgay OC, Farooq M, Hayat R. Seed biopriming with plant growth promoting rhizobacteria: a review. FEMS Microbiology Ecology. 2016;92(8).

9. Anderson NO. Flower breeding and genetics: issues, challenges and opportunities for the $21^{\text {st }}$ century. Springer Science \& Business Media; 2006.

10. Schoenborn L, Yates PS, Grinton BE, Hugenholtz P, Janssen PH. Liquid serial dilution is inferior to solid media for isolation of cultures representative of the phylum-level diversity of soil bacteria. Applied Environmental Microbiology, 2004,70:4363-4366.

11. Badri DV, Weir TL, Van der Lelie D, Vivanco JM, Rhizosphere chemical dialogues: plant-microbe interactions. Current Opinion in Biotechnology, 2009;20:642-650.

12. Badri DV, Vivanco JM. Regulation and function of root exudates. Plant, Cell \& Environment. 2009; 32:666-681.

13. Bais HP, Weir TL, Perry LG, Gilroy S, Vivanco JM. The role of root exudates in rhizosphere interactions with plants and other organisms. Annual Review of Plant Biology. 2006;57:233-266.

14. Bhattacharyya PN, Jha DK. Plant growth-promoting rhizobacteria (PGPR): emergence in agriculture. World Journal of Microbiology and Biotechnology. 2012; 28:1327-1350.

15. Palmisano MM, Nakamura LK, Duncan KE, Istock CA, Cohan FM.Bacillus sonorensis sp. nov. a close relative of Bacillus licheniformis, isolated from soil in the Sonoran Desert, Arizona. International Journal of Systematic and Evolutionary Microbiology. 2001; 51:1671-1679.

16. Trappe JM. AB Frank and mycorrhizae: the challenge to evolutionary and ecologic theory. Mycorrhiza. 2005; 15:277-281.

17. Singh J, Aneja KR (editors). From ethnomycology to fungal biotechnology: exploiting fungi from natural resources for novel products. Springer Science \& Business Media; 2012.

18. Harley JL. The significance of mycorrhiza. Mycological Research. 1989; 92:129-139.

19. Yamuna J, Bagyaraj D, Ashwin R. Response of field bean to inoculation with PGPR Bacillus sonorensis and AM fungus Funneliformis mosseae. Journal of Soil Biology and Ecology. 2018; 38:104-111.

20. Sarma BK, Yadav SK, Singh S, Singh HB. Microbial consortiummediated plant defense against phytopathogens: readdressing for enhancing efficacy. Soil Biology and Biochemistry. 2015; 87:25-33.

21. Porter, WM. The'Most Probable Number'method for enumerating infective propagules of vesicular arbuscular mycorrhizal fungi in soil. Soil Research. 1979; 17:515-519.

22. Cochran WG. Estimation of bacterial densities by means of the "most probable number". Biometrics. 1950;6:105-116.

23. Smith GS, Johnston CM, Cornforth IS. Comparison of nutrient solutions for growth of plants in sand culture. New Phytologist. 1983; 94:537-48.

24. Hatchell GE. Production of bare root seedlings. In: Proc. $3^{\text {rd }}$ Bio. South S.I. Research Conf., 1985; 395-402.

25. Abdul-Baki AA, Anderson JD. Vigor determination in soybean seed by multiple criteria 1. Crop Science. 1973; 13:630-633.

26. Maskina MS, Meelu OP, Roberts DL. Effect of organic and inorganic manuring on rice nurseries. Institute Rice Research Newsletter. 1984; 9:265-75.

27. Kjeldahl JG. Neue methode zur bestimmung des stickstoffs in organischen körpern. Fresenius' Journal of Analytical Chemistry. 1883; 22:366-382

28. Jackson ML. Soil Chemical Analysis Prentice-Hall of India Private Limited M-97. New Delhi, India. 1973;498.

29. Barnes RB, Richardson D, Berry JW, Hood RL. Flame photometry a rapid analytical procedure. Industrial \& Engineering Chemistry Analytical Edition. 1945;17:605-11.

30. Aggarwal M. Experiment-32 Determination of Copper, Zinc, Lead and Cadmium in Food Products by Atomic Absorption Spectroscopy. 2018; IGNOU.

31. Philips JM Hayman DS. Improved procedures for clearing roots and staining parasitic and vesicular-arbuscular mycorrhizal fungi for rapid assessment of infection. Transactions of the British mycological Society. 1970; 55:158-161.

32. Gerdemann JW Nicolson TH. Spores of mycorrhizal Endogone species extracted from soil by wet sieving and decanting. Transactions of the British Mycological society. 1963; 46:235-244.

33. Johnson LF Curl EA. Methods for research on the ecology of soilborne plant pathogens. Methods for research on the ecology of soilborne plant pathogens. Minneapolis, Burgess Publishing Co.1972.

34. Desai S, Bagyaraj DJ, Ashwin R. Inoculation with microbial consortium promotes growth of tomato and capsicum seedlings raised in pro trays. Proceedings of the National Academy of Sciences, India Section B: Biological Sciences. 2019: 1-8.

35. Liu S, Guo H, Xu J, Song Z, Song S, Tang J, Chen X. Arbuscular mycorrhizal fungi differ in affecting the flowering of a host plant under two soil phosphorus conditions. Journal of Plant Ecology. 11;623-31.

36. Takeno K. Stress-induced flowering: the third category of flowering response. Journal of Experimental Botany. 67(17);4925-34.

37. Aboul-Nasr A. Effects of vesicular-arbuscular mycorrhiza on Tagetes erecta and Zinnia elegans. Mycorrhiza. 1995;6:61-64.

38. Heidari Z, Nazari Deljou MJ.Improvement of morpho-physiological traits and antioxidant capacity of zinnia (Zinnia elegance Dreamland Red) by arbuscular mycorrhizal fungi (Glomus mosseae) inoculation. International Journal of Advanced Biological and Biomedical Research.2014; 2:2627-2631.

39. Long LK, Yao Q, Huang YH, Yang RH, Guo J, Zhu HH. Effects of arbuscular mycorrhizal fungi on zinnia and the different colonization between Gigaspora and Glomus. World Journal of Microbiology and Biotechnology. 2010;26:1527-1531.

40. Meyer JR, Linderman RG. Response of subterranean clover to dual inoculation with vesicular-arbuscular mycorrhizal fungi and a plant growth-promoting bacterium, Pseudomonas putida. Soil Biology and Biochemistry. 1986;18:185-190.

41. Jha AK, Pal N, Saxena AK, Singh D, Jha GK. Coinoculation effect of AMF and PGPR on growth and yield of onion. Indian Journal of Horticulture. 2005;63:44-47.

42. Albrechtova J, Latr A, Nedorost L, Pokluda R, Posta K, Vosatka M. 
Sukeerthi, et al

Dual inoculation with mycorrhizal and saprotrophic fungi applicable in sustainable cultivation improves the yield and nutritive value of onion. The Scientific World Journal. 2012; 1-8.

43. Thilagar G, Bagyaraj DJ, Hemlata Chauhan, Anshu Beulah Ram, Ashwin R. Synergistic effects of arbuscular mycorrhizal fungus Glomus mosseae and plant growth promoting bacterium Bacillus sonorensis on growth, nutrient uptake and yield of chilly. Journal of Soil Biology and Ecology.2014;34:50-59

44. Thilagar G, Bagyaraj DJ, Rao MS. Selected microbial consortia developed for chilly reduces application of chemical fertilizers by 50\% under field conditions. Scientia Horticulturae. 2016;198:27-35.

45. Thilagar G, Bagyaraj DJ, Podile AR, Vaikuntapu PR.Bacillus sonorensis, a novel plant growth promoting rhizobacterium in improving growth, nutrition and yield of chilly (Capsicum annuum L.). Proceedings of the National Academy of Sciences, India Section B: Biological Sciences. 2016;1-6.

46. Anuroopa N, Bagyaraj DJ. Selection of an efficient plant growth promoting rhizobacteria for inoculating Withania somnifera. Journal of Scientific and Industrial Research. 2017; 76:244-248

47. Chauhan H, Bagyaraj DJ. Inoculation with selected microbial consortia not only enhances growth and yield of French bean but also reduces fertilizer application under field condition. Scientia Horticulturae. 2015; 197:441-446.

48. Sailo GL, Bagyaraj DJ. Influence of different AM-fungi on the growth, nutrition and forskolin content of Coleus forskohlii. Mycological Research. 2005; 109:795-798. 